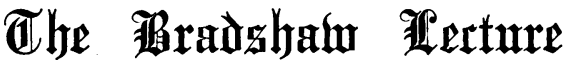

\author{
N
}

\section{THE PLEURAE: PLEURAL EFFUSION AND ITS TREATMENT.}

Delivered begore the Royal College of Physicians of London, November 5TH, 1907.

BY

SIR JAMES BARR, M.D., LL.D., F.R.C.P., F.R.S.E.' SENIOR PHYSICIAN, LIVERPOOL ROYAI, INFIRMARY; VISITING PHYSICIAN, HAYDOCK LODGE AND TUEBROOK ASYI.UIS,

Mr. President and Gentlemen,-We have met to-day to do honour to the memory of a distinguished member of thls College, a memory which has been thus perpetuated by the foundation of this lectureship. Until recently Dr. William Wood Bradshaw was nothing more to me than a name, and even now I know very little more of his personality than what I have gleaned from some old medical directories, and from the first Bradshawe lecture, delivered by the late -Dr. George Vivian Poore, August 18th, 1881. I might, therefore, be allowed to suggest to the members of the Censors' Board, or to some of the historians of the College, that they might usefally while away a little of their spare tlme in writing historical and fairly laudatory sketches of the benefactors of the College. This might encourage others to hand down their names to posterity accompanied by some substantial sums of money.

Whatever may happen in the future, it is to you, Sir, that I owe my selection, and to you I tender my best thanks for the honour which has been conferred on me, and for this opportunity of discussing a medical subject before such a distinguished audience.

The Physics of thin Pridra.

I have chosen the pleura as my text for this lecture, and in doing so $I$ am fully cognizant of the original work which you have done and the brilliant lustre which you have shed, not only. on the pleura, but also on all the diseases of the chest. The somewhat abstruse questions connected with the physics of the chest you have made clear, and your schema of the mechanism of the respiration and the clrcalation in the chest is the best with which I am acquainted.

Diseases of the pleurae, and pleural effasion, have engaged my attention for years, and I think I may fairly claim to have taken some part in the recent advancement jn their treatment. It would be absolucely impossible to do adequate justice to such an important theme in the course of one lecture, so I shall content myself with some practical points which I hope will give you something to think about. Perhaps I should first consider the significance whlch I attach to the word "practical," as different values are certainly associated with $1 t$, and the Britisher. is especially apt to estimate its importance by the pecuniary results. Personally, I think every problem worthy of our attention should be probed to the bottom, and in $\mathrm{my}$ experience the so-called practical men are " often the greatest bunglers, while the theoretical physician is the best practitioner; I am therefore anxious to link myself with the latter however much I may weary you with details, and no matter how unnecessary or impractical these details may be considered.

As you yourself, Sir, have rightly said, " "It would be Impossible truly to comprehend the manifold incidents and conditions of asthma, emphy sema, pleuritic effusion, and pneumothorax without a working knowledge of those statical and dynamical conditions of respiration in health," and therefore I need offer no apology for following such a lead. I must again quote from your expressive language : ${ }^{2}$

When we regard the position and connexions of the pleara, Its extensive endothelisal surface, the conditions of negative pressure in which that extended surface is ever maintained, its richness in lymphatics (indeed the pleural cavitles have, with other sacs of the kind, been regarded ss lymphatic spaces), we cannot wonder that it should frequently become the seat of disease, nor that it should be one of the chosen 3 sites for the manifestation of lesions from blood contamination. Few are the autopsies after adult age in which one fails to find some imperfections in the pleura, few are the cases of septic or pyaemic polsoning in which this membrane is not actively involved.

In addition to its rich supply of lymphatics, the pleura is a fairly blood-vascular membrane, which becomes very evident during an attack of pleuritis. The blood vessels are distributed in the subserous layers. The arteries belong to the systemic system, and are innervated by the sympathetic nerves. The pleura pulmonalis is supplied by the bronchial arteries, and the pleura parietalis receives its supply from the internal mammary and the inter costal arteries. The return current is carried away by the azygos veins. The valves in these veins are very imperfect, and hence when you get high venous pressure in the right auricle and venae cavae, such as arises in tricuspid stenosis, the pressure is transmitted back to the venous radicles In the pleura, and you are apt to get pleural effusion; this is especially likely to occur if at the same time there be a fall in the arterial pressure. The innervation renders the vessels very susceptible to the influence of adrenalin, and of course you are all aware of the ase whlch I have made of this drug in the treatment of serous effusions.

In health there is a slight negative pressure in the pleura owing to the elasticity of the lungs, which even in expiration are in a state of elastic tension and therefore exert traction on the thoracic walls, and, as you have pointed out, there is a tendency. for the thoracic walls to recoil in the opposite direction. I propose to enter rather fully into this subject, as it is in my opinion of much more importance in the treatment of pleurisg than a good many of the drugs in the Pharmacopoeia. The following is copied from Starling's article in Schäfer's Physiology :

We have already seen that, even in conditions of expiration the lungs are still in a stretched condition, and therefore exert a pull on the thoracic wall a until they are allowed to collapse by puncture of the wall. The amount of this elastic force has by puncture of the wall. The amount of this elastic force has
been measured by connecting a mercarial manometer with the been measured by connecting a mercarial manometer with the
traches in the dead body, and then pancturing the thorax. Measured in this way it amounts to between 2 and $5 \mathrm{~mm}$. Hg. According to Donders, however, this is less than the actual pressure in the living body, owing to a loss of elasticity by the Iungs. Donders calculated the elastic pull of the lungs in the expiratory condition as about $7.5 \mathrm{~mm}$. in inpiration this is increased to $9 \mathrm{~mm}$., and after the deepes possible inspiration to about $30 \mathrm{~mm}$. If is evident that these
figures also represent the negative pressure in the thoracic figures also represent the negativ

During ordinsery respiratory movements there are slight
Dury under the same conditions. changes of pressure in the alveoli and tracheal air. In inspiration the pressure in the trachea is from -2 to $-3 \mathrm{~mm}$. $\mathrm{Hg}$ in expiration about $+2 \mathrm{~mm}$. Hg. By connecting the closed traches or air passages with a manometer we may mes closed total possible force exerted by the respiratory musces the dral posin in or exles in amount to -30 to $-74 \mathrm{~mm}$. Hg in inspiration, and to from amount to --30 to $-74 \mathrm{~mm}$. Hg in inspiration, an
about +62 to $+100 \mathrm{~mm}$. $\mathrm{Hg}$ in expiration (Donders).

This is all very well as far as it goes, but, in my opinion, there are many little refinements nccessary when making such observations in the human belng. A good many of the recorded pressures would depend on. the amonit of obstruction to the inflow and outflow of air through the tube in the trachea. The method which I adopt can bo practised by any one on himself without having a tube tied in his trachea. What is required is a little intelligent practice, so as to convert the mouth, the nares, and the intrapalmonary cavity into one aërial space having as nearly as possible the same pressure throughout. . When taking the pressure in the cavity during oral bre athing the mouth is open and the shut nares connected with a manometer. When the pressure is taken during nasal breathing, one or both nostrils are open, and the tube of the manometer lies in the shut mouth. In the observations. It is absolutely essential that all respiratory movements be performed by the thorax alone, and that the month and nares be held in absolute repose. Any sucking or other movement by the mouth or nares destroys the uniformity of the cavity ; of couree, there is a second line of obstruction at the glottis, and the variations in pressure must be grtater beyond the obstruction then in the mouth and nares; but this obstacle cannot readily be removed in the human subject. I give you the following observations made on myeelf, because I can vouch for their accuracy. and 
I think my lungs are still fairly elastic. I know many who would give a better record, and many who would give a worse. These, however, will suffice for the object I have in view. The lower pressures have been made with a water manometer, and the higher with a mercurial; as mercury, is 13.6 times heavier than water, it is easy to convert the readings into water or mercury as you prefer.

Millimetres of Water.

1. Quiet oral breathing: insp. -5 to -8 ; exp. +3 to +5

2. Deep oral breathing: insp. -24 to -37 ; exp. +20 to +30 .

3. Quiet nasal breathing, 2 nostrils: insp. -10 to -16 ; exp. +6 to +10

4. Qaiet nasal breathing, 1 nostril : Insp. -16 to -22 ; exp. +12 to +16 .

5. Deep nasal breathing, 2 nostrils: insp. -40 to -60 ; exp. +30 to +40

6. Deep nassl breathing, 1 nostril : insp. -180 to -200 ; exp. +160 to +180

Miiller's Experiment. - Expanding the chest after deep expiration with the mouth and nostrils closed, $-80 \mathrm{~mm}$. of mqreury.

Valsalva's Experiment. - Forclble expiration with the mouth and nostrils closed after deep inspiration, $+100 \mathrm{~mm}$. of mercury.

If you follow the teaching of most textbooks which dea with thls subject you may infer that the elasticity of the lungs was a constant dragging force trying to separate the two layers of the pleura, and with such a constant force in action of even $6 \mathrm{~mm}$. to $9 \mathrm{~mm}$. of mercury one might naturally expect to find some evidence of its existence. As a matter of fact there is no tractlon but perfect equilibrium, as the elasticity of the lungs is counterbalanced by the intrapleural tension, whlch is equal in force and opposite in direction-the former is positive and the latter negative. The elasticity of the lungs tends to separate the pleural surfaces, and the intraplearal tension, which depends on the elasticity, holds them together. When the lungs are stretched in inspiration the elasticity is increased, and so also is the intraplearal tension by an equal amount.

In the maintenance of this intrapleural negative tension there is a factor in the elastic recoil of the chest walls which has been omltted or not clearly appreciated by physiologists, but which you, Sir, have plainly shown to exist, $80^{3}$

that in quiet inspiration there is no inertia or elastic resistance of the chest walls to be overcome, but thet on the contrary the thoracic elasticity is a reserve force of appreciable power constantly tending to enlarge the thorax, and therefore acting in farour of inspiration.

Moreover, owing to the comparative rigidity of the chest walls and the tenslon of the diaphragm, the externe surface of the pleura is protected from the atmospheric pressure-it is like a membrane lying on the inner surface of a metal ball-and so the two surfaces of the pleura are pressed together, and both lavers are pressed against the internal surface of the thoracic walls by the atmospheric pressure within the langs.

The elasticity of the lungs and the elastic tension or recoil of the chest wall maintain a negative pressure within the pleura, or an intrapleural tension, equal in amount and opposite in sign or direction to that of the elasticity of the langs, so long as there is no fluid in the pleura sufficient to overcome the elasticity, or as long as the pressure within the lungs, minus their elasticity, does not exceed the pressure of the atmosphere.

Let us take 'Donders' figures of $7.5 \mathrm{~mm}$. of mercury or $102 \mathrm{~mm}$. of water as equivalent to the elastic pull of the lungs during the expiratory period, therefore it would require a fluid. pressure all round the lung equivalent to $102 \mathrm{~mm}$. of water, or a depth in the sac equad to this allround pressure, in order to. abolish the elastic pull of the lang. Any further collapse of the lung would be cansed by an increase in the fluid without any positive pressure in the pleara except that of the liquid. When in pleural effusion the intraplearal tension becomes positive-that is, higher than the atmosphere-the lung must be completely collapsed. If the intrapulmonary pressure exceeds that of the atmosphere by $102 \mathrm{~mm}$. of water (a condition which exists in my chest during expiration through one nostril), then the intrapleural negative tension is abolished, and any further rise in the intrapulmonary pressure would keep the surfaces closely glted together, so that the external layer of the pleura might be laid freely open without any risk of air entering the sac. We have seen that great intrapulmonury pressure only occurs when there is some obstruction to forcible expiration such as using only one nostril, or in Valsalva's experiment. It therefore follows that the best way to expand a collapsed lung is to increase the intrapulmonary pressure until you have restored the elasticity of the lung, and then increase the intrapleural negative tension.

Owing to these marvellous provisions of Nature the two lubricated pleural surfaces can move freely over one another, but any force which separates them must be greater than the atmospheric pressure in the lungs during inspiration this is less than the atmosphere, and during expiration rather more. Moreover, the warming of the air in the lungs from $57^{\circ}$ to $98^{\circ} \mathrm{F}$. would make it expand about one-twelfth of its bulk, and this would increase the pressure in the alveoli. It thus takes at least an atmosphere (about $760 \mathrm{~mm}$. of mercury) to separate the two pleural surfaces, and when the surfaces are separated by fluid it must have been secreted at a greater pressure than the atmosphere. Thus any traction from the elasticity of the lungs can have no effect in separating the two pleural surlaces, but any effect is transferred to the walls of the thorax, seeing that there is often 8 difference of pressure on the two sides of the thorax. In the intact chest you never could lower the intrapulmonary pressure suficiently to separate the two pleural surfaces, but in Müller's experiment you can lower the intrapulmonary pressure sufficlently to make its dragging effect readily felt on the walls of the thorax.

If you attach the smooth surface of a worn sixpence with a little vaseline to the bottom of a metal piston of a syringe the sixpence can be easily moved about over the flat surface of the piston, but even when the nozzle is down and the sixpence only suspended by the lubricant (the object of which is to get rid of the air between the piston and the sixpence), you can draw the piston up to the top of the syringe with the nozzle blocked, and thus make a large, though imperfect, vacuum without detaching the sixpence. You can thus see that the elasticity of the lungs is Nature's method for keeplng the two lubricated surfaces close together and enabling them to move freely on one another, and not for separating them, as is often supposed.

Sir William Macewen, F.R.S., in his admirable Cavendish lecture on some points, in the surgery of the lung," segs :

Experience shows that the lang is msintained in fall expen sion by the molecular cohesion existing between the two serous surfaces of the pleurs, and the capillary attraction serous surfaces of the pleura, and the capillary attraction exerted by a thin layer of serous fluid existing between the two moist membranes. Although this molecular force may not be considerable at any given point in the pleura, yet, when it is remembered that it is distributed over the entire surface of the periphery of the langs, its cumulative effect is very great and amply sufficient for the parpose. . . Moleoular cohesion is usually illustrated by the punose clate glass aro Intimate contact ; they cohere, and the truer the suifaces the more perfect the cohesion. Not only do they hold oze another together against the sction of gravity, bat in addition they sustain a considerable weight. This must be attributed to a reciprocal action between the two surfaces, and can have nothing to do with atmospheric pressure, as the experiment succeeds in a vecuum. When, however, the surfaces of the glass are molstened and they are pressed together the cohesion becomes more perfect, and the resistance to separation much greter. If ingtes of notng water the with some fluid whose surface tension was better adapted for with some fluid whose surface tension was better ad
the purpose, the cohesion would become still greater.

In the first place, I should like to add my meed of praise to this excellent lecture. It is the best paper on the subject I have ever read. His surgery is excellent, and, whatever be the forces at work, he recognizes the necessity of keeping the two plenral surfaces in close apposition. Where he sticks to facts there is no ground for complaint, but when he wanders from the region of fact into that of theory we must not allow even this great authority to stand between us and the truth.

He has got a very faint conception of what molecular cohesion really means, and his illustrations have nothing whatever to do with molecular cohesion, but are merely examples of surface tension and atmospheric pressure. The first essential for molecular cohesion is that the molecules must be in contact, and it is absolutely impossible for such contact to take place between two surfaces which are separated by a thin layer of fluid. A layer of less than a thousandth part of an inch in thlckness would 
be 'quite sufficient to prevent molecular cohesion. Chemists and physicists may tell us that molecules are free to move about among one another, but in solid bodies they do not move very far, and contact is essential for cohesion. In the case of the pleura the surfaces glide over one another very easily, and the only difficulty is in the separation of the surfaces. If there were molecular cohesion all movement would be prevented, and the only thing approaching this condition is what Sir William Macewen calls compressive adhesion.

Professor Donnan tells me that the surfaces of two pieces of steel have been cut so true that when they were brought into perfect apposition a much greater force than would be accounted for by atmospheric pressure was required to separate them. This is molecular coheslon; nothing like it occurs between any surfaces in the body. If you had molecular cohesion over such a large surface as the hip-joint, the junction would be so perfect that it would be much easier to smash the shaft than rotate the head of the bone the hundredth part of an inch.

Edward Weber reckoned the atmospheric pressure on the hip-joint at 20 kilos, about $44 \mathrm{lb}$, but I think it must be rather more, as the average surface must be at least 4 sq. in., which would give $60 \mathrm{lb}$. However, a pressure of $40 \mathrm{lb}$. to $60 \mathrm{lb}$. would readily explain all the cohesion phenomens of the joint mentioned by Sir William Macewen.

It is quite conceivable that you might get molecular cohesion "when two sheets of bright plate glass are brought into intimate contact," and in this case they would virtually become one sheet. It is, however, highly improbable that such necessarily true surfaces could be found in plate glass; and, moreover, Sir W. Macewen says that when "the surfaces of the glass are moistened and they are pressed together the cohesion becomes more perfect, and the resistance to separation much greater." This at once disposes of the idea of molecular cohesion, and we have now to consider what holds the surfaces together. Sir William Macewen says:

Not only do they hold one another together against the action of gravity, but in addition they sustain a considerable welght. This must be attributed to a reciprocal action between the two surfaces, and can have nothing to do with atmospheric pressure, as the experiment succeeds in a vacuum.

Here, I am afraid, his experiment is at fault. It is not an easy matter to produce a vacaum, even with a Sprengel pump. The pressure of the atmosphere is roughly $15 \mathrm{lb}$. to the square inch; supposing you reduce the pressure by $14 \mathrm{lb}$., there will still be $1 \mathrm{lb}$. left to the square inch, and it is not often that you will get experimentally a more perfect vacuum than that. Under these conditions you have a pressure of $1 \mathrm{lb}$. to the square inch plus the slight force of surface tension holding the lower plate close to the upper, and the influence of gravity dragging them apart. It is, therefore, simply a question of mathematics. If the weight of the lower plate plus the attached weight exceed $1 \mathrm{lb}$. to the square inch, the plates will separate, otherwise they will remain in contact.

I have made a good many experiments on surface tension, and on the effects of atmospheric pressure, bat I shall only trouble you with a few whlch bear on the subject which we are discussing. The surface tension of a serous effasion having a specific gravity of 1025 will support about 6 grains to the square inch. A transudate of a specific gravity of 1010 will support about 3 grains to the square inch, while the normal thin serous fluid of the pleural cavity may be an excellent lubricating material, but its surface tension will not support more than 2 grains to the square inch; therefore, as a force in holding the two pleural surfaces together, it is scarcely worth cornputing.

I have referred to the experiment of the sixpence attached with a little vaseline to the bottom of the metal piston of a syringe. The same event occurred when I substituted $8+\frac{1}{4}-0 \mathrm{z}$. weight and $\frac{1}{2}-0 \mathrm{z}$, welght; but when I used a 1-oz. and a 2-oz. welght each of them dropped off when the vacuum exceeded a certain degree. The cohesion does not continue when the influence of gravity exceeds the atmospheric pressure plus the surface tension in the partial vacuum. To further test the force of the atmospherlc pressure in holding surfaces together, I used different metal weights, and finally took a 56.1b. weight, coated one of its rough surfaces with a layer of vaseline, and then laid on this a polished bookshelf. I then struck the bookshelf so as to drive out the excess of vaseline, and bring the two surfaces as closely together as possible. I steadily raised the bookshelf and the $66 \mathrm{lb}$. remained attached, and I thus carried it round the room. I next Interposed a sheet of paper coated on both sides with vaseline between the weight and the bookehelf, and still the $56 \mathrm{lb}$. remained attached while it was thus carrled about. In these experiments the two surfaces could be moved easily over one another. I do not suppose that any one will imagine that the surface tension of vaseline is capable of supporting $56 \mathrm{lb}$; but to clear up any doubt in the matter I shall tell you of an experiment which, so far as I am aware, has never been carried out. Take a block of marble of $1,000 \mathrm{lb}$. weight, having a perfectly smooth polished surface of about 1 gquare foot in area; the under surface must be rough, and rest on a hard irregular surface so that a column of air may be below the greater part of the under surface. On the smooth upper surface; spread about an ounce of vaseline; then apply a strong, rigid, perfectly-smooth metal plate of rather more than a square foot in size, strike the metal plate with a sledge-hammer so 8 s to bring the two surfaces into close apposition Then slowly and steadily raise the metal plate with a pulley, and the block of marble will follow it. If anything will show the force of the atmospheric pressure this should. You may ask me how I know that this experiment will succeed. I know that the atmospheric pressure is about $15 \mathrm{lb}$. to the square inch, and if you only oppose that with a weight of $7 \mathrm{lb}$. to the square inch you leave a good margin for the success of the experiment.

In punctured wounds of the thorax the pleural surfaces are often not separated. The writer on intrapleural tension in Clifford Allbutt's System of Medicine says:

Where the wound is a small one and only a puncture though the lung be injured the sir as a rule does not fine access to the pleurs, but crosses the pleurs and resches the subcutaneons tissue. The reason of this is very difficult to find, but of the fact there is no doubt.

I do not know if any of you have encountered a man who was making indiscriminate use of a knife. I have, and for a short, time I got the worst of the conflict. If you should meet such an individual you can deal with him as you think best, but if you find him making a lunge for your chest I would strongly advise you to let your breath ont before he does it for you. In this way the knife or dagger has another inch to travel before it reaches your chest, and you establish a positive pressure within yourthorax, which prevents the two pleural surfaces from separating. After the injury keep the wounded side as much as possible in a state of expiration, and do not on any account take \& deep insplration.

I know a medical man who opened both pleurae in a patient within a few days of each other for empyemata, and the patient recovered. I am afraid he did not know much about the elasticity of the lungs or he would not have shown such temerity. He thinks that the pleural surfaces were extensively adherent, and thus collapse was prevented. The Increased intrapulmonary pressure during expiration tends to expand the collapsed lung and to obliterate the actual cavity.

Mr. Arthar Edmunds has recorded ${ }^{5}$ some very interesting observations on a case of pneumothorax in a chlld when the chest was laid freely open. He also made many illustrative experiments on cats. In the child and also in the cats the respiration became triphasic.

The first phase was an inspiratory effort; this filled the lnng on the sound side with air ; the lung on the affected side collapsed. The second phsse was an expiratory effort, and during this time the affeoted lung was seen to fill with air, and to struggle in Its effort to expand against the remgining band The atr which filled this lung to from the healthy lung, as it was unable to escape to the exterior owing to the closure of the glottis. In the third phase the glottis opened, the expiratory effort continued, and air passed to the exterlor from both lungs. The passage from The three phases mey be briefly termed insplration distribation, expiration.

When the air enters the pleural cavity from the lung the exit is usually not so free as the inlet, so the intrapleural tension, both in inspiration and expiration becomes positive, and so the lung collapses, and does not get a chance of expanding again unless the perforation hesl and the air. get absorbed. After withdrawing serous fluid from the pleura I frequently produce an artificlal 
pneumothorax, but I am carefal not to produce any positive intrapleural pressure.

In cases of pleural effusion of course the pressure is as the depth of the liquid, but when the lung is free to float the intrapleural pressure does not become positive until the elasticity of the lung is overcome. The heart becomes somewhat displaced, as you, Sir, have pointed out, even before the pressure becomes positive, being drawn over by the greater negative pressure in the other side of the chest. Then with the further increase in the liquid the pressure becomes more and more positive and displaces the other organs. With the substitution of the fluid air for the liquid effasion you can more easily regulate the pressure. In empyema the pressure is frequently higher than in simple effusions; and when the tension is very high you may have the puleations of the heart communicated to the liquid, giving rise to a pulsating empyema.

We have seen how the lung is kept expanded by the negative tension within the pleura, and the greater and more active the inspiration the greater the negative pressure, but not unfrequently, especially in many wasting diseases where the demand for oxygen is not great, this negative pressure may fall to a very low ebb or may disappear, so that partial atelectasis of one or both lungs, or almost complete atelectasis of one lung is not at all uncommon. This is especially apt to occur in young flat-chested individuals with pliant chest walls. Perhaps I have seen a greater number of these cases than has fallen to the lot of most men, for the simple reason that for many years I have been on the look-ont for them. These cases are freguently overlooked because there is usually a negation of subjective chest symptoms, and so the lung is often allowed to remain so long collapsed that it never completely expands, and afterwards the deficient expansion of one side of the chest is supposed to be the result of some old pleural effusion of which the patient has no recollection. When these cases are discovered in the early stages they are usually mistaken for pleural effusion-an error which is apt to remain uncorrected if an exploring needle be not inserted into the chest. I show you the skiagraphs of a couple of cases which were tapped in several places with a negative result, and afterwards such diagnosis as sarcoma of the lung, unresolved pneumonia, etc., arrived at. My opinion that the conditions were simply due to atelectasis which could be removed by respiratory gymnastics was at first received with credulity, but the subsequent improvement in the cases avd the nonfulfilment of the grave prognostlcations proved the correctness of my views. I have seen this condition occur in typhoid fever, infective endocarditis, pyaemia, etc. In one severe case of typhoid fever an energetic consultant came to the conclusion that a mistake had been committed, and that he had to deal with a case of empyema, but he had to acknowledge his own mistake when he found the pleura quite empty. I had sub. sequently the opportunity of explaining the correct nature of the condition, which in this instance was cared by making the patient lie on his other side. In the following case I made a mistake myself :

My colleague, Mr. R. A. Bickersteth, had removed some taberculous glands from the right ilise fosse in a youth who was under the care of Dr. Steeves. A few days after the operstion the boy got an oscillating temperature, and although there was no boy got an oscillating temperature, and although there was no respiratory distress it was found that the right side of the
chest was quite dull. I was asked to see the patient with chest was quite dull. I was asked to see the patient with dall from base to apex, absence of respiratory murmur, and no rocal phenomens. I rapidly came to the conclusion that the right pleura was full of fluid, which I thought should be drawn off, although there was no urgent necessity for interference The following de $\mathrm{Mr}$. Bick ersteth made gereral punotares bat fonnd nothing 作 arrived at the correct solution of the problem. The youth got erfectly well under a course of resplratory gymnastics.

In exhausting diseases, when the patient has lain for long time in one position, a partlal atelectasis is apt to take place, which is often mistaken for hypostatic congestion of the lung. Under fairly similar conditions a true congestion of the lung frequently takes place, but the two states are easlly differentiated. In advanced c3ses of mitral stenosis collapse of numerons lobnles in the posterior surface of both lungs is a matter of frequent occurrence. In these cases the oxidlzing surface is greater than that demanded by the small quantity of blood passing through the lungs. Such cases usually pass on to more or less permanent collapse with brown induration of the lungs. Apart from cases associated with "mitral stenosis, atelectasis, partial or complete, when early recognized, is very amenable to treatment; but when long neglected more or less permanent damage to the lung results, just. as occurs when the lung has been long collapsed by a pleural effusion.

With care atelectasis is easily differentiated from pleuraI effusion even when the dull percussion is absolute and the respiratory and vocal phenomena absent. In atelectasis of one lung the affected side is smaller than the other, the ribs are closer together and more sloping, the costal angle more acute, the diaphragm raised, the dull percussion. barely reaches the middle line in front, while the sound lung passes bey ond the mesial line, the heart is either not displaced or slightly pushed over by the sound lung. Forcible rubbing of the affected side, acting through the lung reflex of Albert Abrams, causes some expansion of the lung and clears up the percussion note. This is also accomplished by forcible expiration, or better by. Valsalva's method. Every one who has attended a case of parturition knows how a vigorous child expands its lungs, and in the treatment of atelectasis in the adult you cannot do better than imitate Nature, minus the howl.

ETIOLOGY OF l'LEURISY.

The question of the etiology of each particular case of pleurisy should be settled as far as possible, as it is a most important point both for treatment and prognosis. I suppose every case is due to some micro-organisms or their toxins; even those cases following injury or cold have only thus been rendered valnerable. This also applies to those cases associated with some chronic illness, such as granular kidney, or those due to extension Irom the pericardium or peritoneum. The vast majority of cases are tuberculous, but a considerable number are rheumatic, or due to pneumococci, streptococci, staphylococci, the Bacillus coli, typhoid bacilli, and the influenza bacilli, etc. Many of these organisms are readily found in the serous effusion, but not so with the tubercle bacillus. It is often difficult in any given case to decide whether it be tuberculous or not. If you find any evidence of tuherculous disease in the lungs, or tubercle bacilli : in the sputum, yon may consider the question settled. Failing this direct evidence you should add a little citrate of sodium to the fluid withdrawn to prevent coagulation, then centrifuge, and examine the sediment for leucocytes, tubercle bacilli, and other micro-organisms. If the case be tuberculous the cells will be mostly lymphocytes, whereas if the pleuritis be due to other micro-organisms, the polymorphonuclear cells will predominate. Even in undoubted tuberculons cases you generally fail to find the tubercle bacilli, and the injection of the fluid into the guines.pig is a very slow and often impracticable test. A blood count often assists; as in tuberculous pleurisy there is no leucocytosis, whereas in that associated with other processes there usually is. A haemorrhagic effusion is usually associated with tuberculous or malignant ailsease. A specific gravity of 1018 is generally put down as the divlding line between a transudate and an exudate, but it does not always hold good, as in some undoubtedly inflammatory cases I have found the specific gravity of the fluld as low as 1006

Cases of dry pleurisy are frequently tuberculous, though not necessarlly so. In such cases there is a small effusion of plastic lymph, which is gelatinous in appearance and consistence, and contains a large number of cells with a relatively small amount of fibrin. This effasion quickly organizes, and joins the two pleural surfaces together. In taberculous cases accompanled by effusion there is not much fibrin, and even the cellular elements may be small in amount. In pneumococcal pleurisy there is usually a large amount of fibrin whether there bo much fluid or not. Those cases associated with streptococcl, staphylococci, and Bacilliss coli are frequently purulent or sero-purulent, and contain a large number of cells, and in the case of the Bacillus coli the fluid is very cffensive. In cases of transudation the liquid contains a few endothelial cells and not much fibrin, and the specific gravity is below 1018. There are many cases, such as those arising in chronic Bright's disease, when the effused fluid is a mixture of a transudate and an exudate.

I am not going to weary you with sympromatology or diagnosis-3s I shall take it for granted that you know as. 
much about those enbjects as I do-so we will now pass on to treatment.

Treatment.

Cases of dry pleurisy require very little treatment except some counter.irritation, a diaphoretic, a purgative and perhaps a sedative to relieve pain, or some strapping of the chest to limit the amount of movement.

I wish to take this opportunity of emphasizing the princlples which underlie my methods of dealing with effusions into the pleural cavities. At the present time this is the more necessary, as I find that I have got a few imitatorg, who have never seen me treat a case, but who think the whole method consists in withdrawing more or less of the effused fluid and injecting a little adrenalin colution. I am not surprised when I hear that they do not attain the success which I may say almost invariably follows my efforts.

In the treatment of pleural effasion the question often arises, When should you withdraw serum? This is rather an important question, and one which is more easlly asked than answered. You know that if the effugion be not very great it often gets absorbed alter the febrile stage passes off, with or without any special medication. Mauy devices have been advocated to hasten the absorption, with more or less success. Being naturally of a conservative frame of mind, I do not care for meddlesome interference with natural processes, consequently I sometimes give Nature a longer chance than is perhaps advisable. The effasion is a natural process, which, if it continue till after the inflammation has subsided, lessens the risk of pleuritic adhesions ; it also keeps the collapsed lung quiet, which is very desirable if there be any active taberculosis in the lung. A very large proportion of cases of pleurisy are tuberculous, and the early withdrawal of fluid causes vascular turgescence of the lung, oiten hastens the dissemination of the tubercle bacilli, and kills the patient. Before I began the substitution of one fluid for another by the introduction of air into the pleural cavity I was much more chary of early tapping than I am at present. I can now remove the whole of the effusion, even in tuberculous cases, at an early stage with perfect impunity. A considerable number of deaths have followed the complete withdrawal of effusion in elderly persons with rigid chest walls. The danger in such cases arises from establishing too great a negative pressure which leads to hyperaemia;and oedema of both lungs; this can be obviated by the introduction of air. I now recom. mend the complete withdrawal of the effusion in all cares, but before any great negative pressure is established, and before the patient feels any discomfort, I stop the siphon and introduce about an equal quantity of air to the amount of fluid which I have withdrawn. I then reestablish the"siphon and complete the withdrawal of the effusion. When all the liquid is withdrawn I inject 4 c.cm. of adrenalin solution $(1$ in 1,000$)$ diluted with 8 or $10 \mathrm{cccm}$. of sterile normal saline; and, if I think it necessary, I introduce more sterile air, so as to make the total amount equal to half or three-fourths of the bulk of the fluid withdrawn; the larger quantity of air is Introduced in tuberculous cases. By this method the patient suffers no discomfort except from the slight thrust of the trocar. I prefer the siphon to the aspirator because you can readily regulate the force of the suction, and as your tube only reaches to a receptacle on the floor prac. tically your negative pressure never exceeds $1 \mathrm{lb}$. to the square inch; this force is greatly exceeded by the aspirator, and the greater the negative pressure the greater the risk of secondary hyperaemis or oedema. It is an advantage to introduce a manometer in the air tube as you can thus avoid producing any positive pressure in the pleura. Of course all aseptic precantions are taken. (I now exhibit my apparatus for this treatment.*)

The adrenalin solution is introduced to contract the blood vessels and lessen the secretion. According to Schäfer, Elliott, Brodie and Dixon, adrenalin only acts on unstriped muscular fibre which is innervated by the sympathetic; the'pleural vessels belong to the systemic system and are thus innervated, but its effect is not very prolonged, consequently you cannot expect it to lessen the secretlon for any great length of time if there be a great negative pressure in the pleura. Although I had very good success from its use before I commenced the introduction of air. I soon recognized the limits of its

* Manufactured by R. Sumner and Co., 53A, Lord Street, Liverpool. inefulness. When you remove four or five pints of serous fluid from the pleura there is a potential or actual cavity left which cannot be filled by a drachm of any fluid. Such a cavity cannot exist in the human body with a surrounding atmospheric pressure of $15 \mathrm{lb}$. to the square inch. It is filled by:.(a) The carbonic acid gas which escapes from the serous fluid; (b) by the more or less expansion of the collapsed lung; (c) by the return of the mediastinal contents which were pushed or drawn to one side, and the further expansion of the other lung; $(d)$ by increased quantity of blood in the chest; $(e)$ by elevation of the diaphragm; and $(f)$ by falling in of the chest wall. All these events may not suffice to fill the cavily il the amount of fluid withdrawn have been very great, and the lung be so collapsed and bound down that it cannot expand. In this case the negative pressure is very great, and under such circumstances it would be absurd to expect adrenalin or anything else to permanently check the secretion. When the use of adrenalin is supplemented by the introduction of air, the negative pressure is lessened or abolished, and the lung gradually expands as the air gets absorked. By this combined method you can operate early in any case, even during the febrile stage, and under no circumstances should you allow the fluid to accumulate to such an extent as to completely collapse the lung; you should tap before the patient suffers any respiratory distress. By the removal of the effusion you often remove an enormous number of micro-organisms, and by the introduction of sterile air you substltute a light innocuous fluid for a heavy and deleterious one.

Dr. W. Ewart of London has recently been injecting adrenalin solution into the pleural fluid preparatory to drawing it off, and he has had good success in thus stimulating the absorption of the effused fluid.

I always like to treat the individual rather than his disease, consequently I thy to avoid routine, and I make such modifications in treatment as will suit esch indlvidual case. When the pleurisy is practically cured you will find plenty of scope for ingenuity in trylng to restore the function of the lung to its pristine vigour. I have no time to enter into the numerous respiratory exercises which I from time to time recommend, but there is one which each of you can try on himself, the marked effect of throwing one serratus muscle into and the other out of action. You can also stady my observations on the conditions of intrapulmonary pressure in the different stages of respiration. The function of a physician used to consist in prescribing drugs and giving some directions about diet, but fortunately these dass have passed for ever. I have not told you anything about drugs, though I am a firm believer in their efficacy when a ppropriately used, as I have not got any specifics for pleural effusion. There is one drug, common salt, which you should as far as possible eliminate from the diet, especially in cases of serofibrinous pleurisy, on account of its high osmotic equivalent When you hear men telling you that they gave 10 minims of something or other three times a day, and the fluid dissppeared as if by magic, you can envy such credulity. but it is impossible to admire it. Like a good many of my countrymen, I am rather critical, and have not sufficlent faith where the action of drugs is concerned. If you say to an Irishman, "I hope the medicine has done you good." you will not infreqpently get such a reply as : "Well, thank God, it has done me no harm, anyhow." That is about the value which I attach to drugs which are given to cause absorption of a serous effusion in the pleural cavity.

When there is a large quantity of effused fibrin, such as occurs in pneumococcal pleurisy, decalcifying agents such as lemons, citric acid, the citrates of ammonium, potassium, and sodium, may be used. However it will be well to reserve the use of these drugs until the acute stage of the accompanying pneumonia has passed, as the lime calts are exceedingly useful in that dicease.

In order to hasten the solution and absorption of the effuged fibrin I see no objection to the introduction of trypsin into the pleural cavity. I am engaged in investigations with reference to the limitation or prevention of pleural adhesions. With this object in view I am at present injecting into the pleural sac liquid paraffin, which has a lower specific gravity but a higher surface tension than the normal lubricating fluid. The results of my observations will be given at a later date. 
I shall now give a short account of the history of the introduction of adrenalin and air into the pleural cavity. In August, 1902, I saw regularly, in consultation with Dr. Chisholm, Mr. F. T. Paul, and Mr. R. A. Blckersteth, a lady who was suffering from secondary cancerous deposits in the pleura with effasion. The fluid had to be withdrawn every four days, and it reaccumulated so quickly that she had scarcely a day free from distress in breathing between the aspirations, and I saw that this state of matters could not contlnue long. Necessity is the mother of invention, and I began to consider how to lessen this secretion. I came to the conclusion to try an injection into the pleural cavity of the suprarenal extract, and I fixed upon Parke, Davis and Co.'s adrenalin chloride, 1 in 1,000 , as being a sterile preparation. I empirically fixed 1 drachm, or 4 c.cm., as the amount to be injected, and after the fifth aspiration this quantity was used. There was no further secretion, consequently no further tapping, and the old lady spent the remainder of her life In perfect comfort, as far as the chest was concerned. In her memory her husband contrlbuted $£ 12,000$ to establlsh the Liverpool Cancer Research Fund.

Since this case I have injected 1 drachm of adrenalin solution into every pleura which I tapped, and in only two cases have I had to draw off the fluid a second time. Soon after I began this method-to which no one has laid a prior claim-I commenced in additlon the introduction of sterilized air to replace the fluid which I had withdrawn. I was led to adopt this procedure by the distress frequently caused to the patient by any attempt to withdraw all the serum; by the usually rapid reaccumulation, especially when there was any negative pressure left in the pleura, or there was a large potential or actual cavity owing to the lung being so collapsed or bound down that it could not expand ; by the great risk of collateral hyperaemia and oedems of one or both lungs, especially in those persons with rigid chest walls; and by the fact that in tuberculous cases there is apt to be a rapid dis semination of tubercle through the lung when the pleural pressure is removed. As four-fifths of the air is nitrogen, whlch is only slowly absorbed, this air pad tends to prevent or lessen pleural adhesions. Since I began the substitution of air for serum I have been able to withdraw the whole of the liquid with perfect impunity.

I exhibited my first and second apparatus for the introduction of adrenalin and air into serous cavities at the Liverpool Medical Institution on November 5th 1903, and the following week there was a notice of my apparatus in the proceedings of the Medical Institution published in the weekly medicsl journals.

In the British Medical Jodrnal of March 19th, 1904, I published a clinical lecture on the Treatment of Serous Effusions, in which I fully described my method and apparatus for treating effusions into all the serons cavities. At that time the idea of injecting sterllized air was quite original so far as I was concerned;'and some of the leading members of the medical profession to whom I spoke on the subject had never heard of any such practice, but I afterwards found that some others, to whose writings I shall presently refer, had been in the field before me.

In the Edinburgh Medical Journal of November, 1886, Dr. Theobald A. Palm published an account of 3 cases In which he allowed air to be sucked into the pleural cavity after aspiration. One case recovered after one tapping, another after two, and the third case took an unfavourable course, and in the course 'of some months the patient died.

On April 24th, 1888, M. Potain communicated to the Academy of Medicine, Parls, a successful case of pyopneumothorax treated by the injection of sterilized air after the removal of the liquid. His object was to keep the lung compressed until the pleuro-pulmonary fistula had healed, and to prevent the reproduction of the liguid.

In Italy several papers appeared between 1888 and 1902 on the introduction of air into the pleural cavity by Drs. G. Lava, G. Cavallero, 8. Riva-Rocci, and Prolessor Forlanini.

About or before 1900 Professor Ayerza and his pupil, Dr. Bungé of Buenos Aires, treated cases of acute and ehronic tuberculous pleurisies by the abstraction of the liquid and the Injection of oxygen gas. They used oxygen as a specific medication against the tubercle bacilli, but as oxygen is more readily absorbed than nitrogen, in no case did the pneumothorax last longer than fourteen days. Recently Professor Forlanini has advocated the treatment of phthlois by the repeated introduction of oxygen gas into the pleural cavity so as to maintain an artificial pneumothorax and thus rest the lung. About a century ago a somewhat similar treatment of phthisis was carried out in Liverpool by the late Dr. Carson and Mr. Robert Bickersteth. They produced pneumothorax by an external opening into the pleurs, but they soon gave up the practice.

At the Société Médicale des Hôpitaux de Paris (May 23rd, 1902) MM. Vaquez et Quiserne reported two cases of chronic pleurisy successfully treated by aspirating the liquid and injecting in each case 3 or 4 litres of sterile air. One case had been previously asplrated twelve times, and the other five.

In the Gazetta Medica Italiana; March 3rd, 1904, there appeared a communication on thoracocentesis with the introduction of sterllized air after the method of Professor Forlanini, by Dr. Antonio Pisani. He records the case of a child of 9 years of age from whom he removed $1,600 \mathrm{ccm}$. of fluid, which had probsbly been in the pleura for eleven weeks. During the operation he insufflated 1,000 c.cm. of air filtered through cotton-wool slightly impregnated with formaldehyde. At the end of the operation part of the air was removed by aspiration.

In the Lancet, November 10th, 1906, there is an editorial reference to a case reported at a meeting of the Société Médicale des Hôpitaux de Paris on October 12th, 1906, by M. Dufour and M. Foix. They successfully removed a large chronlc pleural effusion and injected sterile air.

Dr. W. Ewart has recently allowed filtered air in a Woulfe's bottle to be sucked in by the chest. In my original apparatus I used a large Woulfe's bottle, but I drove in a measured quantity of filtered air by a falling column of sterile water of a few inches in height. Th1s, in my opinion, was a perfect apparatus, but it was too cumbersome to carry about.

This systematic treatment of pleural effusion by the combined method of the complete withdrawal of the liquid, and the introduction into the pleural sac of adrenalin and sterile air, ${ }^{*}$ which I may fairly claim to have originated, will, I hope, be more appreciated as it becomes better known. The adrenalin solution; is better dhuted with two or three times its bulk of normal galine solution.

\section{EMPY FMa.}

This is one of those numerous disesses which the surgeons have taken under their own special care, but they have done nothing to advance its treatment-I presume because physics seem to have formed no part of their education. In the case of a child with elastic chest walls you could not easily mismanage a case of empyema. A considerable number of cases get well in spite of treatment. When a surgeon has to deal with a purulent effusion in the chest, about the only Idea which he can get into his head is free drainage, and forthwith out comes a plece of $\mathrm{rlb}$ and in goes a large drainage tube; he expects it to suck up the liquid from the most to perhaps the least dependent part of the cavity, utterly reckless as to whether the collapsed lung ever expands again or not. Dr. Otto Grünbaum has devised a useful appliance for assisting the lung to expand in these mismanaged cases, bat I do not know of any surgeon who has taken it up. Mr. Arthur Edmunds, to whose valuable work I have pre. viously referred, insists on the anaesthesia being very light when operating on an empyema, so as not to abolish the pleuro-laryngeal reflex, and thus the vocal cords are enabled to play their part in maintaining the pressure within the lungs.

If I were a surgeon and had to deal with sach a case I would use a local anaesthetic, such as eucaine; or, if thought necessary in any particular case, light general anaesthesia as recommended by Mr. Arthur Edmunds; I would make a free incision in a very dependent spot, about the eighth or ninth intercostal space, in a line with the lower angle of the scspula. If the ribs were close together it would be well to take out a long piece of one rib and then make a very free incision into the pleura. An assistant should firmly compress the side so as to drive the purulent matter out and allow as little air as * I have in a few cases used oxygen, but as a rule I prefer air,
because it is more slowly absorbed 
possible to enter the chest during the operation. A strip of gauze may be inserted in the wound to keep it open, but no tube should be introduced; I would then apply a large piece of sterile oiled silk over the wound to act as a valve, so as to allow the fluid to escape and no air to enter. Large aseptic dressings should be applied over the valve. The affected side may be well strapped to prevent movement. I would make the patient lie on or towards the affected side, so as to lessen movement and encourage drainage, prevent him taking any deep inspirations, and tell him to make deep nasal expirations, so as to expand the affected lung and drive the purulent fluid out of the pleural cavity. He should be instructed to inspire through the mouth and explre through the nose. I would also make him frequently practise the Valsalva method, or blow through a small tube. If the pus be very offensive or not draining well, the patient can be treated in a continuous bath and then no dressings will be required.

In these cases the pus is usually fairly liquid, is neutral, or may even be slightly acid in reaction, contains some peptone and a ferment which seems to have the power of idigesting fibrin, and thus the lung is not likely to be rreparably collapsed or bound down by adhesions; there is, therefore, a fair chance of success if the operation be adopted early, and after-treatment intelligently carried out.

The variety of micro-organisms in the pus should be ascertained, and an appropriate vaccine, after the method of Sir A. E. Wright, should be used. Even the stinking empyemata from the Bacilius coli often do very well. Tuberculous cases are the most troublesome, and usually when the fluid becomes purulent there is a mixed infection. Cases of pyopneumothorax are best treated by drawing off the fluid and filling the cavity with sterile air or oxygen. Where the empyema is loculated the surgeon may remove a plece of the rib and use a drainage trube if he choose; he cannot do much harm. Unfortunately, Estlander's operation is often necessary, partly owing to early mismanagement of the cases. There must be some effort made to place the treatment of this disease on a more scientific basis than that on which it at present stands.

I have spoken strongly about the surgeons because I feel strongly, and I am anxious that they should remove this blur from their escutcheon. The old wheeze about the physicians not handing the cases over soon enough is now played out. There is still, however, plenty of work for the physicians; prevention is better than cure, and I think in the future their work should lie more and more in that direction. Our aim should be to protect the individual from the ravages of disease and the onelaught of the surgeon, and make the very existence of that individual less and less of a necessity. 2 Diseases of the Lungs and Pleurae. By Bir R. Douglas Powell, Bart.
Fourth Edition, 1893, p. 1.2 Ibid., p. 93. 3 Ibid., p. 10. 4 BRITISH Meurth JodR JAL, July 7th, 1906. 5 ibid., November 2ist, 1903.

\section{CEREBRO-SPINAL MENINGITIS COMPLICATED BY PARTURITION.}

By J. D. WILLIAMSON, M.D.,

PHYSICIAN FOR DISEASES OF CHILDREN AND OBSTETRICS, ULSTER HOSPITAL FOR CHILDREN AND WOMEN.

THE following case of cerebro-spinal meningitis during pregnancy is interesting from more than one point of view-the age and condition of the patient; the sudden onset of cerebro-spinal meningitis when the patient was in labour (whilst at the same time she declared that she did not know what was the matter with her and would not admit she was pregnant); its rapid course, leaving no time for any very active treatment to be of any service; the look of the patient, the character of the petechial and herpetic eruptions, without head symptoms, and the persistent vomiting, which, being in this case associated with pregnancy, did not command the amount of attention that under other circumstances it would have received.

M. W., who was in a neighbouring town up till Christmas, 1906, then returned home to a street in a working-class locality of Belfast. She was aged 13 years and 9 months, her mother giving the age in evidence at the Coroner's Court as 14 years on May 23rd, 1907. She was admittel on March 5th, 1907, 10 the maternity department of the Ulster Hospital for Diseases of Women and Children as $b$ :ing in labour. She had always been a strong, healthy girl, well developed, and had never menstruated.

The history of the case as reported to me was that on March 5th, about 2 a.m., the patient was seized with violent pains in lower part of back and abdomen, accompanied with vomiting; the pains were paroxysmal, and she became so ill that a doctor was sent for about 4 a.m. He prescribed and gave some instructions to give her some relief, and later on returned, accompanled by another medical man; on consultation both agreed that the patient was in labour, but this she denied, protesting against anything of the kind. Her mother expressed her astcnishment, as she never thought such a thing possible, owing to her age and appearance; the patient absolutely refused to give any information regarding her condition to any one.

The patient was admitted to the Ulster Hospital at noon, when the temperature was $101^{\circ}$, the pulse 100 , full and bounding, strong uterine contractions occurred at intervals of about ten minutes; there was no vomiting, there was slight mucoid diarrhoea, the cheeks were slightly cyanosed; there was herpes about the nostrils and mouth but no rash at this time, the tongue was furred but moist, the pupils reacted normally; she had a wild, frlghtened appearance, was quite conscious, and complained of no pain in the head. The vagina was moist and dilatable, the os very sllghtly dilated, and the presentation vertex but very high up in the pelvis.

The patient remained in much the same condition antil 2 p.m., when the pains became almost continuous, the breathing was very rapid and distressed, the cheeks and lips more deeply cyanosed, the pulse rapid and irregular. I was at"this stage summoned by telephone to see the patlent, who was reported as being in the maternity ward and in labour. Almost immediately I had a second message to say patient was in a state of collapse, and replied to give a hypodermic of strychnine. I went immediately, and found the patient in bed lying on her right side; the legs were flexed on the thighs and the thighs on the abdomen, and the forearm on the arm ; she was conscious, pupils elightly dilated and equal, the face cyanosed, the breathing rapid and difficult, and the pulse quick and irregular; she was to all appearance in labour, was re:vous and frightened-looking, but did everything she was asked.

I had her turned on the left side and made a vaginal examination; the passage had the feeling as if contracting on the finger, the rugae being well defined, the of, which was elightly dilated, admitting the tip of $\mathrm{my}$ finger with difficulty. I was able to make out the presentation a vertex, with the left hand on the abdomen I could feel the uterus hard and contracting. Her attitude and appearance did not harmonize in my opinion with the stage of labour, and I felt that there might be ome leskon in the chest. On examining the chest $I$ arrived at the opinion that there was well-marked congestiton of both lunge; tho heart was rapid and irregular. but I was nnable to make out any valvular lesion. I was unable ito procure a sample of urine. Neither the facenor extremitics were oedematous. She was very sensitive to the touch (hypereesthetic). The breasts. were well developed, the secondary areola was well marked, and on pressure finid exuded through nipples. The fetal heart sounds were heard very indistinctly, but I c bserved fome dark gpots over the lower part of the abdomen and thighs. I learned that these had developed since her admission to hospital; they were dark in colour, irregular in shape and size, oome flat, others raised like a small blister, and on pressure the colour did not disappear; these, with her look and condition, sugge日ted cerebro-spinal meningitis. She very quickly got worse, though still remaining perfectly conseious, complaining only of the uterine contractions and pain in the back; there was no pain in the head, but great pain and difficulty in swallowing, and heavy breathing. Dea th supervened about 3.50 p.m.

The patient's condition was so serious when I first saw her that I felt no obstetrical interference would prove of any service, or obviate a fatal result to either mother or child. Rapid dilatation of the 08 and removal of the fetus might have been attempted, but I felt that had I 